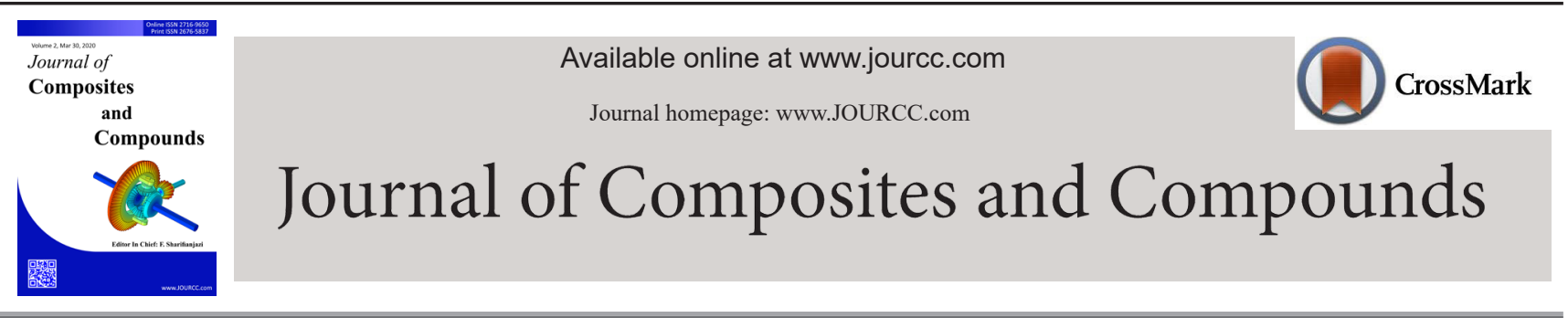

\title{
Hydroxyapatite consolidated by zirconia: Applications for dental implant
}

\author{
Fariborz Sharifianjazi ${ }^{a}$, Amir Hossein Pakseresht ${ }^{b}$, Mehdi Shahedi Asl ${ }^{c}$, Amirhossein Esmaeilkhanian ${ }^{a}$, \\ Hiva Nargesi Khoramabadi d, Ho Won Jang ${ }^{e}$, Mohammadreza Shokouhimehr ${ }^{e *}$
}

${ }^{a}$ Department of Materials and Metallurgical Engineering, Amirkabir University of Technology, Tehran 15875-4413, Iran ${ }^{b}$ Coating Department, Centre for Functional and Surface Functionalized Glass, Alexander Dubcek University of Trencin, Trencin 91150 Slovakia ${ }^{c}$ Department of Mechanical Engineering, University of Mohaghegh Ardabili, Ardabil, Iran

${ }^{d}$ Department of Medical Engineering, Payame Noor University (PNU), Alborz 19395-3697, Iran

${ }^{e}$ Department of Materials Science and Engineering, Seoul National University, Seoul 08826, Republic of Korea

\begin{tabular}{|c|c|}
\hline A B S T R A C T & A R T I C L E IN F O R M A T I O N \\
\hline $\begin{array}{l}\text { Zirconia has garnered significant attention as a new ceramic material for dental implant due to its excellent } \\
\text { biocompatibility, strength, and promoting the oral rehabilitation with high aesthetic, biological and mechanical } \\
\text { properties. It also expedites the amelioration of bone minerals surface by its bio-integrative ingredients which } \\
\text { are naturally close to ceramic intrinsic of bone. Alternatively, hydroxyapatite (HAp) has prevalently been used in } \\
\text { dental implant due to its high biocompatibility. However, it generally shows weak strength and mechanical prop- } \\
\text { erties. Consequently, incorporating zirconia and HAp produces appropriate composites for dental implant having } \\
\text { improved physiochemical properties. This review provides discussions addressing the methodologies and ex- } \\
\text { emplars for the designed composites used in dental implant applications. The representative methods for surface } \\
\text { modification of zirconia incorporating HAp (i.e. sol-gel, hot isostatic pressing, plasma spraying, electrophoretic } \\
\text { deposition, etc.) is highlighted. The advantages, disadvantages, biocompatibility, strength, and osseointergration } \\
\text { and biointegration properties of the presented composites are explored. } \\
\text { C2020 JCC Research Group. } \\
\text { Peer review under responsibility of JCC Research Group }\end{array}$ & $\begin{array}{l}\text { Article history: } \\
\text { Received } 25 \text { November } 2019 \\
\text { Received in revised form } 02 \text { January } 2020 \\
\text { Accepted } 27 \text { February } 2020\end{array}$ \\
\hline \multicolumn{2}{|l|}{ able of contents } \\
\hline \multicolumn{2}{|l|}{ I. Introduction...... } \\
\hline Dental implant & 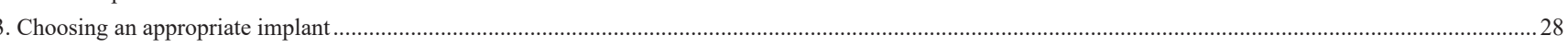 \\
\hline \multicolumn{2}{|c|}{ 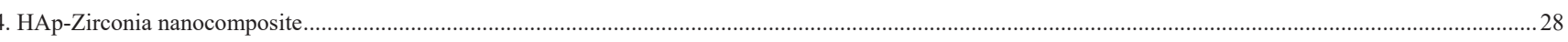 } \\
\hline \multicolumn{2}{|c|}{ 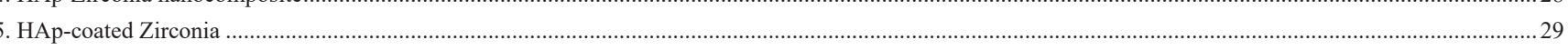 } \\
\hline \multicolumn{2}{|c|}{ 5.1. Hot isostatic pressing method } \\
\hline \multicolumn{2}{|l|}{ 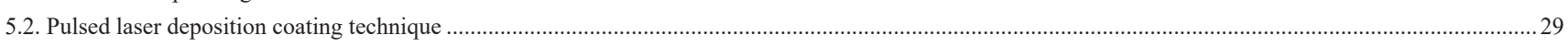 } \\
\hline \multicolumn{2}{|c|}{ 5.3. Sol-gel technique } \\
\hline \multicolumn{2}{|c|}{ 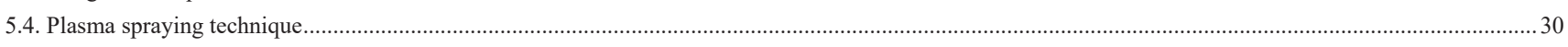 } \\
\hline Electrophoretic deposition ................... & \\
\hline Sputter coating metho & \\
\hline
\end{tabular}

\section{Introduction}

Dental composites have been confirmed as safe component for filling rotted teeth, principally because of their superior aesthetics and biocompatibility [1-5]. They are typically composed of resin matrix and inorganic fillers [6-8]. Although considerable investigations have been carried out to improve the monomer structures and filler formulations, secondary caries and rebuild fractures of dental composites are the major reasons to repair failure. The accessible fillers cannot present expected strengthening and useful impact in dental composites. Thus, more endeavors have been made to produce fillers providing similar function and structure to the natural human teeth [9].

Recently various materials have been utilized in the field of hard

*Corresponding author: Mohammadreza Shokouhimehr; E-mail: mrsh2@snu.ac.kr DOR: 20.1001.1.26765837.2020.2.2.4.2

https://doi.org/10.29252/jcc.2.1.4 This is an open access article under the CC BY license (https://creativecommons.org/licenses/by/4.0) 
tissue engineering [10-12], e.g. hydroxyapatite (HAp) [13], bioactive glasses, bio-ceramics [14], bio-scaffolds [15, 16], etc. Among them, HAp has crystallographic and chemical similarity to human bone tissues, therefore, has extensively been utilized for bone-related issues. It contains calcium phosphate possessing chemical formula of $\left[\mathrm{Ca}_{10}\left(\mathrm{PO}_{4}\right)_{6}(\mathrm{OH})_{2}\right][17-19]$.

In addition, HAp is very well-known biocompatible substitution for the essential mineral constituents of skeletal bones that can be utilized as orthopedic surgeries and tooth implant [20,21]. HAp is considered to be extremely bioactive, osteoconductive, biocompatible, non-toxic, non-immunogenic, and non-inflammatory [22, 23]. The measurement of alkaline phosphatase activity has indicated that naturally isolated HAp can to be utilized for progression of both cell proliferation and differentiation [17]. Therefore, various chemical routes have been introduced for HAp synthesis including hydrothermal, sol-gel, mechano-chemical, precipitation, and polymer-assisted methods. HAp can also be fabricated from bio-waste or natural resources including clam shell [24], bovine [25], camel bones [26], corals [27], cuttlefish [28], and fish bone [17, 29].

It is noteworthy that the HAp coating application is one of the most promising surface modification method applied for dental implant. The HAp-coated implants have been widely utilized in dental applications due to their great biocompatibility with epithelium, and bone and connective tissues. A thin layer of HAp is used to coat the dental implant surface, which has been generally observed to be effective for the osseointegration process, load stress distribution, healing time to bone, bone implant contact, and bone crest repair [30]. Moreover, the HAp coating can improve the mechanical properties of the substrates; in particular, the surface biocompatibility and maintaining the load-bearing capacity. For example, the histology study and mechanical interface characteristics of HAp coated titanium and commercially pure (CP) titanium, revealed that the HAp coating enhances the mean interface stability of bead-blasted CP titanium system with no coating five to eight times [30]. HAp coated implant can also interact with the surrounding biologic environments. For dental materials, the importance of HAp coatings, due to their developed integration of osseous tissues, has been also improved for implant surfaces. These materials can play a role in the sources of phosphate and calcium in the enamel minerals in supersaturation state. Furthermore, they can protect the outer dental enamel caries lesion by mineralization system [30].

This review focuses on the effect of HAp incorporation either in the form of coating or composite incorporated zirconia. It discusses zirconia implant, nanocomposites, and surface modification techniques to enhance the bio-integration and osseointegration treatment of zirconia-based implant [31].

\section{Dental implant}

Implant dentistry is a prosthetic effort via a surgical procedure [32, 33]. In order to achieve an ideal prosthetic construct, precise plan should be taken into consideration prior to the beginning of treatment. The position of implant requires protected prosthesis. It can be affected by the implant size, volume, and the quantity and quality of bone provided at various sites [34].

Another parameter that requires to be integrated in to therapeutic deliberations is the measurement of accessible horizontal and vertical space for prosthesis adaption. Various reports have indicated the functional and aesthetic success of this therapy for up to six years of longterm follow-up [34]. In the field of dental implant, handful materials such as pure Ti and some of its alloys, zirconia, and tantalum have been found as appropriate implant materials up to now. The indication of osseointegrated implant in the bone is not closely discoverable mobility. Moreover, osseointegration should be protected during the lifetime of the implant owing to its effectiveness [31].

Biointegration has been described a sort of the interconnection between the recipient tissue and a biomaterial at the microscopic measurement. This connection among implant and tissue is a region of interaction or a specified boundary between the corresponding tissue and biomaterial [35]. Osseointegration is the presence of highly proximity between the supporting bone and the implant without including fibrous tissue or collagen. However, continuity of the implant to bone with no intervening space is known as biointegration. In fact, the ceramic-based implant chemical degradation should occur in the biointegration process for development of bone generation as well as integration of the ceramic implant around the bone?. The nature or mechanism of both operations are not entirely understood so far, and their superiority over each other is not recognized very well. There is similarity between both interfaces are natural teeth clinical alkalosis. Although the ceramic has been coated on metallic implants primly enhance a bio-integrated interface, the interface stability is lower as a result of its degradation with time in long term [31] (Fig. 1).

In the past decades, the development of nanocomposites has opened new prospect in different fields to obtain materials with enhanced physical and mechanical properties [36, 37]. Because the nano-HAp has greater surface area and higher reactivity as a biomaterial compared with its bulk counterpart, it can provide significant characteristics in several medicinal fields, in particular, dental implant. The effect of HAp incorporation as coating materials in dental implants have been hopeful for
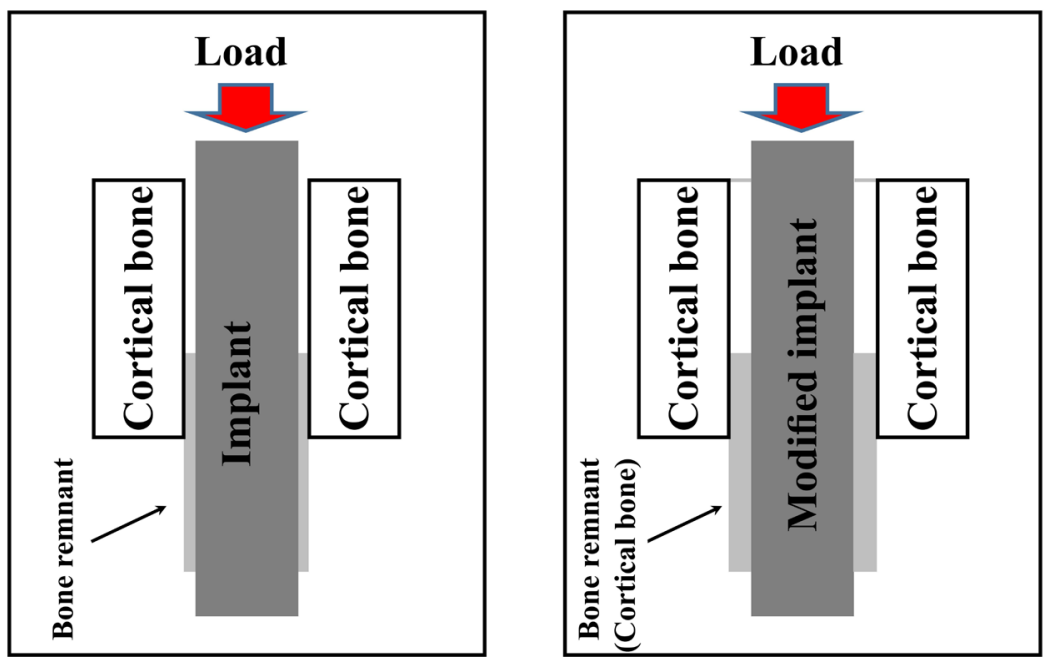

Fig. 1. Schematic illustration of implant vs. surface modified implant 
futures applications. It can result in formation of chemical bond with bone and lead to reinforced biological and biointegration fixation [31].

\section{Choosing an appropriate implant}

Fabrication of dental implant is highly utilized with Titanium and titanium alloys due to corrosion resistance and high strength [38]. However, novel implant technologies are being improved, due to aesthetic compatibility and potential immunologic with titanium implant. Meanwhile, $\mathrm{ZrO}_{2}$ implant is considered as an alternative to Ti-based implant in dental implantology. $\mathrm{ZrO}_{2}$ has shown to be more effective as implant material $[39,40]$.

Zirconia $\left(\mathrm{ZrO}_{2}\right)$ is oxide form of a gray white, lustrous, strong transition metal named Zirconium (Zr) [41, 42], and has emerged as an alternative to common Titanium based implant for oral rehabilitation with higher aesthetic, biological, optical and mechanical properties [39]. In addition, Zirconia is very interesting because of its potential osseointegration and having other superior properties such as white color and translucency that mimics the natural teeth. It is radiopaque same as $\mathrm{Ti}$ and can be observed under radiography. Compared to Ti, bacterial colonization around $\mathrm{ZrO}_{2}$ is seemed to be lower. Some investigates have indicated that zirconia has higher biocompatibility in comparison with $\mathrm{Ti}$, as the latter fabricates corrosion products at the implant site [43].

Although many studies have been performed for titanium implant compared to zirconia in the past decades, high-strength zirconia ceramics have attracted a great attention as new materials for dental implant. This ceramic indicates minimal ion diffusion compared to metallic implants (i.e. Titanium), which mentioned to be inert in human body. Due to its biocompatibility, mechanical properties and tooth-like color, zirconia have become a superior dental implant material. Surface topography and material composition of a biomaterial in osseointegration act a fundamental role. One of the main agents in the surface of implant is their quality that effects healing of wounds at the implant placement and afterward influences osseointegration. Thus, different physical and chemical modifications of surfaces have been advanced to promote osseous healing [44].

The clinical application of zirconia dental implants is restricted owing to difficult modifications of surface. In addition, implant with smooth surfaces are disadvantageous for osseointegration due to weak tissues interaction [44]. Because bone consists of ceramic phase, a ceramic system with proper mechanical properties, which provides the mineral growth on its surface can be called the right biointegrative material. The zirconia implants with modified topography were investigated and their biointegration by laser modification, UV modification and methodologies like surface modifications were explored [45].

\section{HAp-zirconia nanocomposite}

Matsumoto et al. [46] studied a composite of HAp-incorporated zirconia having micro porous structure. Their results showed that the produced composite material possessed strength in the range of bio-cortical bone strength with high tissue and cell affinities by combining HAp and $\mathrm{ZrO}_{2}$. It was found that by changing the molding pressure and raw materials particle size, control the quality of surface is feasible, proposing this material as a good candidate for bone restoration. Izquierdo et al. [47] deposited $\mathrm{HAp} / \mathrm{ZrO}_{2}$ composites on Ti-21Nb-15Ta-6Zr alloy through pulsed layer deposition and investigated their electrochemical properties. Results showed that the presentation of HAp/zirconia layers avoids the interaction of the biomaterial with active molecules and the subsequent reduction oxidation and enhances interaction between bone tissue and implant. The $\mathrm{HAp}-\mathrm{ZrO}_{2}$ coating modifies the Ti alloys electrochemical features in Ringer solutions. The prepared film had good bioactivity through generating an appetite layer similar to bone material and can be offered as a promising material for orthopedic and dental implants. The produced $\mathrm{ZrO}_{2} / \mathrm{HAp}$ composite film indicates excellent surface roughness and energy and significant wettability compared to $\mathrm{Zr}$ substrate.

Bulut, et al. [48] investigated biocompatibility of HAp-zirconia and HAp-alumina composites and a ternary component of commercial inert glass. Results showed the great mechanical properties of the $\mathrm{HAp}-\mathrm{ZrO}_{2}$ composites as well as the development of bioactive properties. According to the obtained results, the ternary composites can be mentioned as promising materials for bone-related issues.

Buciumeanu et al. [35] deposited composite layers of bioactive zirconia on zirconia structures and investigated their tribological properties. The layer of bioactive zirconia composite (zirconia containing 10 vol. $\%$ of $\beta$-TCP or 10 vol. $\%$ of HAp) was successfully provided by press-sinter method on zirconia substrate. Their results showed that zirconia composites had a great potential to be utilized as a biomaterial in dental implants with a layer of the bioactive zirconia composite, due to great mechanical properties and developing bond between the implant and living tissue. The advantage of bioactive zirconia composite layer is that it is a suitable substitute to coatings on zirconia substrate due to decreasing the possibility of implant failure and the interfacial residual stresses.

Leong et al. [49] prepared nanocomposites of HAp/yttria stabilized zirconia (YSZ) under for dental materials. HAp/YSZ nanocomposites were obtained by wet ball milling and sintering pressureless and also under pressure using nitrogen gas. However, HAp decomposition was found to take place in the samples regardless of the sintering methods. In spite of the sintering techniques that investigated, relative density of 99.5\% without identifiable HAp decomposition was attained only with the hot isostatic sintering technique.

Carvalho et al. [50] functionalized zirconia surface by HAp using hybrid laser method for applications in dentistry. Their results showed that the improvement of novel procedures for promotion of the implant biointegration and its long-term retention is challenging. The procedure attempts to mimic the natural bone material. By altering atmosphere and energy density, textured surface could be designed. Moreover, high volume of sintered and maintained bioactive material was produced when the process was carried out with low scan speed and high laser power.

Gergely et al. [51] studied microstructural and mechanical properties of $\mathrm{ZrO}_{2} / \mathrm{HAp}$ nanocomposites obtained by spark plasma sintering (SPS). To prevent the reaction between $\mathrm{ZrO}_{2}$ and $\mathrm{nHAp}$ and decomposition of $\mathrm{nHA}$, the SPS method was carried out at short dwelling time (5 min) and low temperatures. It was shown that the mechanical and microstructural characteristics of the composites were strongly dependent on SPS technique specialties.

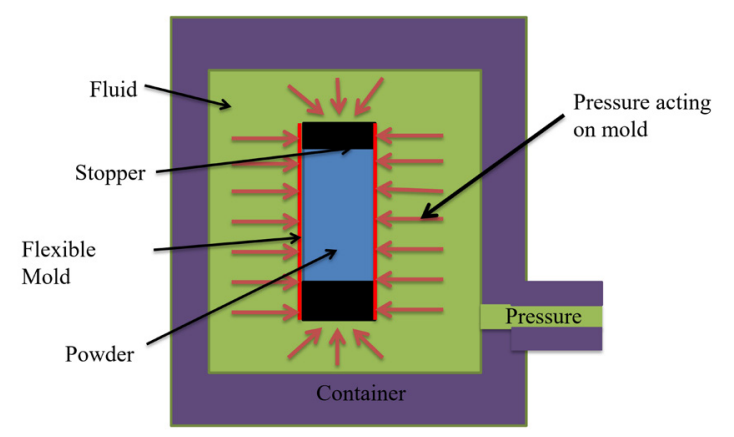

Fig. 2. Schematic of HIP method. 


\section{HAp-coated zirconia}

Nowadays, many studies have focused on corrosion [52] and coating [53], especially importance of ceramic coatings as dental implant to enhance osseointegration. Different forms of ceramic coatings have been utilized on implants for dentistry over the last 15 years including inert ceramics such as zirconium and aluminum oxides and bioactive ceramics including bioglasses and calcium phosphates. Coatings can be porous or dense depending on their production procedure with a thickness ranging from 1 to $100 \mu \mathrm{m}$. Various ceramic coating methods in dental implants include sol-gel [54-56], hot isostatic pressing (HIP), plasma spraying [57-59], electrophoretic deposition [60], sputter-deposition and pulsed laser deposition [61].

\subsection{Hot isostatic pressing method}

In HIP, isostatic temperature and pressure are applied simultaneously. Contrary to hot pressing, a uniform pressure is exerted in different directions (Fig. 2). HIP is used to create metals and ceramics, such as highdensity ceramics and composites, components with complex shapes and it is utilized for the solid phase bonding of different or similar materials. The sample is in a gaseous medium and undergoes heat treatment accompanied by a high pressure for consolidation. One of the significant benefits of HIP is the high flexibility in specimen shape.

There are many reports concentrating on pressure sintering techniques including hot pressing (HP) and HIP to maintain the $\mathrm{ZrO}_{2}$ and HAp phases during sintering process and decrease the sintering temperature. Moreover, pressure sintering techniques are argumentative methods with diverge conclusions and studies regarding the phase stability of the phases. Although an enhancement in reactivity are anticipated because of enhanced contact areas between diffused $\mathrm{ZrO}_{2}$ particles and HAp matrix, there is a common agreement that the composite is significantly constant particularly after HIP. Indeed, in the composites obtained by hot pressing, a partial reaction between zirconia and HAp occurred, although, much fewer than what observed in sintering in air yet. Hence, the sintering environment can be a major factor influencing the $\mathrm{ZrO}_{2}$ and HAp thermal stability in the composites [30]. Leong et al. [62] synthesized HAp/zirconia composites and investigated HAp decomposition for the application as dental materials. Their results indicated that HIP of $\mathrm{HAp} / \mathrm{ZrO}_{2}$ could greatly inhibit HAp decomposition and the highest relative density was achieved compared to other techniques.

Ergun et al. [63] prepared composites of HAp/zirconia using HIP and studied their phase stability. According to the results, phase stability of $\mathrm{ZrO}_{2}$ and $\mathrm{HAp}$ in hot isostatically pressed composites was indicated. Higher $\mathrm{ZrO}_{2}$ contents and lower sintering temperatures led to lower density in air-sintered specimens. The amount of air in the environment of sintering affects the reactivity between $\mathrm{HAp}$ and $\mathrm{ZrO}_{2}$. To achieve phase stability and fully-dense $\mathrm{HAp} / \mathrm{ZrO}_{2}$ composites, HIP would be a suitable technique.

Lim et al. [64] studied sintering of HAp incorporated zirconia using different methods including HIP, solid-state reaction, conventional sintering and microwave sintering. They proposed that HIP revealed more satisfying results compared to other methods. Furthermore, nano structured material can be processed by alternative techniques and show better results.

\subsection{Pulsed laser deposition coating technique}

Laser texturing methods has been widely investigated to modify materials surface for various applications. This method is a hopeful method to progress the direct sintering of $\mathrm{HAp}$ on $\mathrm{ZrO}_{2}$ substrates in order to produce appropriate coatings. It is known that mechanical interlocking produced through laser texturing is able to enhance the stability of the coating interfaces, therefore preventing delamination of coating during the implants insertion [65].

Mesquita-Guimarães et al. [65] sintered HAp coatings and 45S5 bioactive glass on micro-textured $\mathrm{ZrO}_{2}$ via laser and evaluated osteoblasts-like cell adhesion. In vitro test indicated that, compared to flat surfaces, the squared textured pattern possessed bioactive coating and $100 \mu \mathrm{m}$ width grooves provided an increase of $90 \%$ of cell viability after incubation for 48 hours. Hence, they showed that laser sintering is an attractive and fast method for HAp coatings.

Carmen Trincă let al. [66] studied the electrochemical properties of a novel biodegradable FeMnSi alloy coated by HAp-zirconia through pulsed laser deposition (PLD) method. Their results showed that the corrosion resistance enhanced significantly for alloys coated with HAp$\mathrm{ZrO}_{2}$ in comparison with uncoated sample.

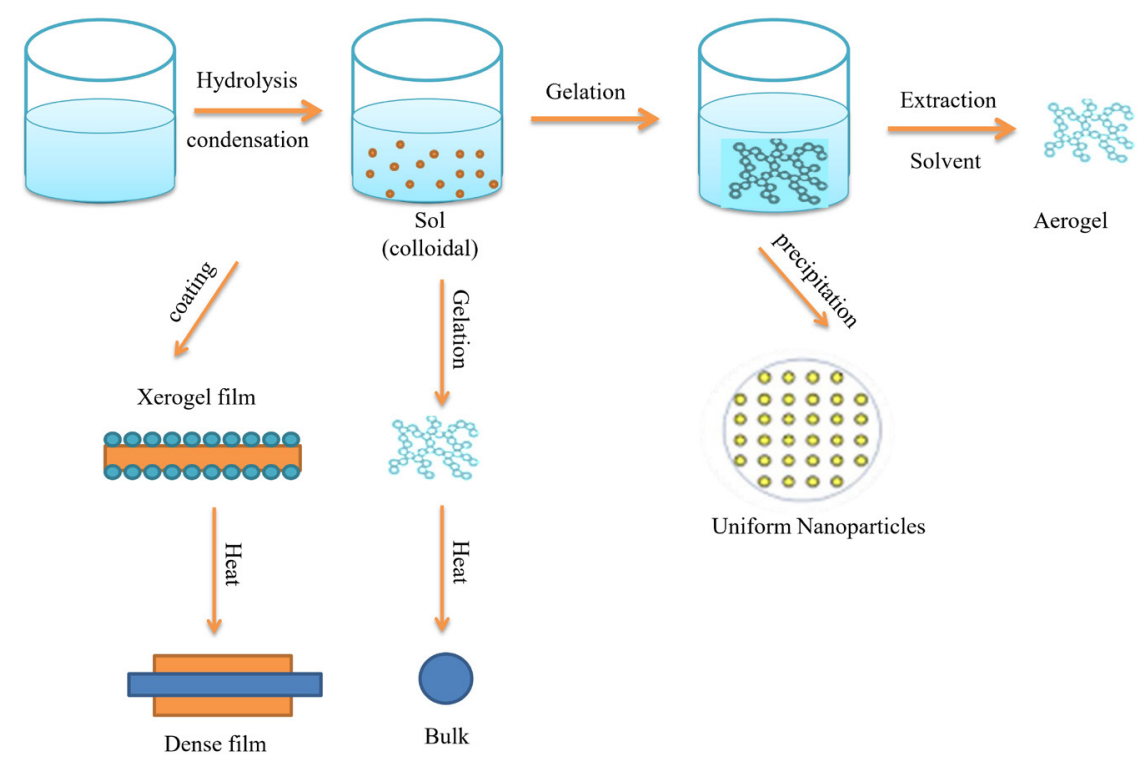

Fig. 3. Schematic illustration of sol-gel technique. 


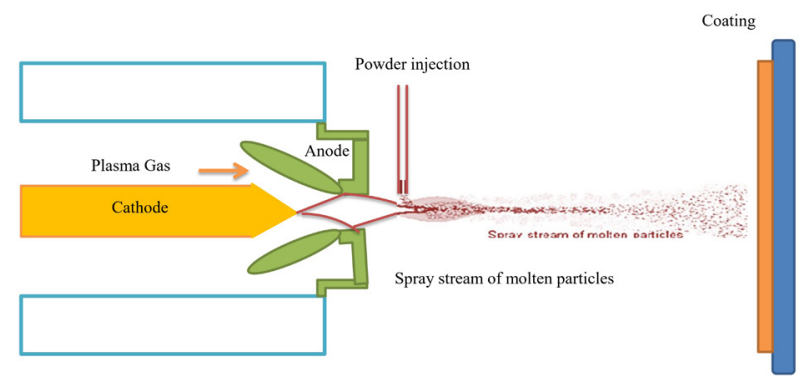

Fig. 4. Plasma spraying technique schematic illustration.

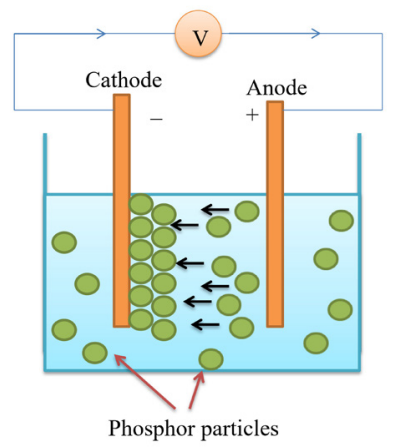

Fig. 5. Electrophoretic deposition process schematic.

Hybrid laser method was employed by Carvalho et al. [50] to functionalize zirconia surfaces by HAp for dental applications. The textures that were generated by Nd:YAG laser were produced to promote the mechanical interlocking of HAp particles, hence reinforcing its incorporation to surface of $\mathrm{ZrO}_{2}$. For optimization of the textured pattern of $\mathrm{ZrO}_{2}$ surface, various laser parameters were tested. Hybrid laser process was proposed to have the potential for modification and functionalization of zirconia surfaces.

\subsection{Sol-gel technique}

The sol-gel procedure is a wet chemical technique in which high temperatures or $\mathrm{pH}$ values are not required [55, 67-70] (Fig. 3). Significant reactivity owing to the large surface area of dried gels leads to a low procedure temperature $[71,72]$. In addition, this technique can promote chemical homogeneity by providing a molecular mixing precursor solution. Due to its intrinsic benefits over other processes, nowadays, the sol-gel process has been highly utilized for fabricating of ceramics. The process permits the provision of a homogeneous combination of YSZ and HAp nanoparticles.

Vasconcelos et al. [73] studied the microstructure of $\mathrm{HAp}-\mathrm{ZrO}_{2}$ nanocrystalline composites prepared by sol-gel method. Their results showed that optimizing processing parameters could produce HAp$\mathrm{ZrO}_{2}$ nano-crystalline composites. The modified sol-gel process could produce a water vapor atmosphere during sintering which could control the HAp thermal stability and provide a high intergranular dispersion of $\mathrm{ZrO}_{2}$ phase in the HAp matrix [73].

Salehi, et al. [74] studied Properties and fabrication of sol-gel isolated $\mathrm{HAp} / \mathrm{ZrO}_{2}$ composites nanopowders by different yttria contents. Homogeneous composites of HAp/yttria-stabilized zirconia (HApYSZ) nanopowders were produced by the sol-gel technique. Due to ion exchange of zirconium and calcium between zirconia and HAp, the HAp unit cell volume enhanced in the composites. The existence of $\mathrm{ZrO}_{2}$ nanoparticles between the HAp particles inhibited the HAp grain growth and also the inhibition of the $\mathrm{ZrO}_{2}$ grain growth was resulted from yttrium ions segregation at the grain boundaries.

In Bollino et al. [75] research, biphasic composition of HAp and the surface modification with a tricalcium phosphate (TCP) was carried out

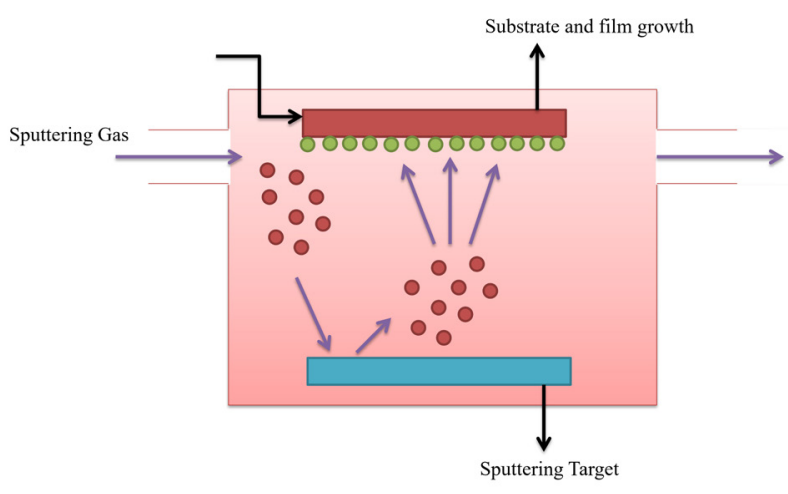

Fig. 6. Schematic of sputter coating method.

on a zirconia substrate by utilizing a sol-gel technique. The microstructure of the conclusive HAp/TCP coatings was found to be related on the sort of zirconia substrate. The heat treatment temperatures of coating on dense and porous zirconia substrates were $750{ }^{\circ} \mathrm{C}$ and $1350{ }^{\circ} \mathrm{C}$, respectively. In the case of dense substrate, a thick layer of nano HAp was formed, but cracking and agglomeration were observed.

Catauro et al. [76] studied thermal and morphological characterization of the composites of HAp incorporated zirconia for biomedical applications, obtained through sol-gel method. According to the obtained results, the crystallization of $\mathrm{Zr}$ in the tetragonal phase occurred due to existence of HAp in the composite. Moreover, by increasing the $\mathrm{Zr}$ content in the composites the degree of amorphization increased.

Jin et al. [77] applied biocompatible and bioactive calcium phosphate layer on zirconia surface. $\mathrm{HAp} / \mathrm{ZrO}_{2}$ composites were prepared by the sol-gel technique and heat-treated at various temperatures in order to modify their chemical structure. They indicated that all materials are bioactive, consequently they can generate a HAp layer on their surfaces. Furthermore, biocompatibility enhanced with heating temperature, while the amount of HAp did not affect it significantly. On the other hand, bioactivity improved with both heat-treatment temperature and the HAp content.

Buciumeanu et al. [35] coated zirconia by zirconia/HAp composite and studied its tribological properties. Their results showed that press and sinter technique on YSZ substrates could significantly influence the performance of composite layer of bioactive zirconia. According to the results, by adding bioactive materials, the tribological characteristics and the friction coefficient were not influenced. The focus of this novel procedure on zirconia substrate was on the application of bioactive zirconia composite layer. Since there is a gradual change between the substrate and composite layer, it seems to be a suitable replacement for coatings due to reduction in interfacial residual stresses and hence it is less prone to failure.

\subsection{Plasma spraying technique}

One of the promising techniques of preparing coatings with special microstructural characteristics is solution precursor plasma spraying (SPPS) method (Fig. 4). Various studies have reported about SPPS method that promotes the HAp coatings. It is possible to achieve higher contents of HAp in coating with changing spraying parameters e.g. spraying distance $[78,79]$. Different substrates including mild steel has been coated by HAp using air plasma spray technique [80, 81].

Hasan et al. [82] studied the mechanical properties of HAp coatings on $\mathrm{Zr}$ using plasma spray technique. $\mathrm{ZrO}_{2} / \mathrm{HAp}$ composite coating on $\mathrm{Zr}$ by plasma spraying illustrated that compared to pure zirconia, the incorporation of HAp in $\mathrm{ZrO}_{2}$ enhanced biological properties, whereas its biocompatibility is preserved. On the other hand, plasma sprayed 
Table 1.

Various techniques used for coating $\mathrm{HAp}$ on $\mathrm{ZrO}_{2}$ substrates.

\begin{tabular}{|c|c|c|c|}
\hline Method & $\begin{array}{l}\text { Coating } \\
\text { thickness }\end{array}$ & Advantages & Disadvantages \\
\hline Electrophoretic deposition & $0.1-2 \mathrm{~mm}$ & $\begin{array}{l}\text { Control of coating thickness/ morphology, low cost, rapid } \\
\text { deposition, simple setup, uniform coating thickness, suit- } \\
\text { able for complex shaped substrate }\end{array}$ & $\begin{array}{c}\text { Decomposition of HAp during sintering stages, appear- } \\
\text { ance of crack in coating, high sintering temperature } \\
\text { requirement }\end{array}$ \\
\hline Sputter & $0.5-3 \mu \mathrm{m}$ & High adhesion, dense and uniform coating on flat surface & $\begin{array}{l}\text { Produces amorphous coating, low deposition rate, line } \\
\text { of sight technique, costly, time-consuming }\end{array}$ \\
\hline plasma spraying & $<20 \mu \mathrm{m}$ & $\begin{array}{l}\text { Quick bone healing, less possibility of coating degradation, } \\
\text { high deposition rate, low cost }\end{array}$ & $\begin{array}{l}\text { Unable to form complete crystalline coating, relatively } \\
\text { weak adhesion, non-uniformity in coating density, } \\
\text { phase change and grain growth of the material because } \\
\text { of high temperature, change of HAp structure during } \\
\text { coating }\end{array}$ \\
\hline Sol-gel & $50-400 \mathrm{~nm}$ & $\begin{array}{l}\text { Very thin and high purity coatings, low processing tem- } \\
\text { perature, high corrosion resistance, suitable for complex } \\
\text { shaped substrate, uniformity in coating }\end{array}$ & $\begin{array}{c}\text { Expensive raw materials, high permeability, difficult to } \\
\text { control porosity, requirement of posttreatment (curing), } \\
\text { Appearance of edge cracking }\end{array}$ \\
\hline $\begin{array}{l}\text { Pulsed laser deposition } \\
\text { coating }\end{array}$ & $0.05-5 \mu \mathrm{m}$ & $\begin{array}{l}\text { Control of deposition factors, amorphous and crystalline } \\
\text { coatings, suitable for porous, dense coating }\end{array}$ & $\begin{array}{c}\text { Line of sight technique, requirement of pretreatment of } \\
\text { surface, lack of uniformity, expensive, low deposition } \\
\text { rate }\end{array}$ \\
\hline HIP & $0.2-2.0 \mathrm{~mm}$ & $\begin{array}{l}\text { Good temperature controlling, dimensional limitation, } \\
\text { dense coating, no shape }\end{array}$ & $\begin{array}{l}\text { Reaction of encapsulation material with HAp coating, } \\
\text { incompatibility of thermal expansion coefficient, } \\
\text { costly, requirement of high temperature, unable to coat } \\
\text { complex shaped substrate }\end{array}$ \\
\hline
\end{tabular}

coatings suffer from residual stress and lack of uniformity in coatings on complex-shaped Zr implants.

\subsection{Electrophoretic deposition}

Electrophoretic deposition is a coating method, in which through the influence of an external electric field colloidal particulates migrate and are deposited on an electrode (Fig. 5). Ceramic coatings are able to be produced by this technique and the method has the capability to be used for complex objects coating due to being cost-effective and flexible. This approach allows controlling of the microstructure, thickness and composition of coatings hence electrophoretic deposition is a useful method especially in the HAp deposition [30].

Sandhyarani et al. [83] fabricated nanostructured $\mathrm{ZrO}_{2} / \mathrm{HAp}$ coating on zirconium and studied in-vitro performance of manufactured composites. HAp particles were dragged into the evacuation channels, during the film growth step, then by electrophoretic deposition process entrapped into the oxide film. Due to residing of $\mathrm{Ca}$ (generating from HAp melting) in $\mathrm{Zr}$ sites, zirconia is stabilized. After immersing in SBF for 8 days, apatite layer similar to bone was formed on all surfaces of $\mathrm{ZrO}_{2} / \mathrm{HAp}$ films showing their considerably increased in-vitro bioactivity. The cell adhesion test results indicated that the human osteosarcoma cells on the surface of $\mathrm{ZrO}_{2} / \mathrm{HAp}$ film could propagate, append and adhere very well [84].

Sakthiabirami et al. [85] coated a composite of glass/zinc-HAp on glass-infiltrated zirconia to tailor interfacial interaction. The surface stabilization of HAp ( $\mathrm{Ca}^{+2}$ cations) was done by chemical adsorption of non-dissociated 2-propanol and monochloroacetic acid (MCAA) molecules through $\mathrm{Cl}^{-}$followed by protons dissociation, leading to negatively charged HAp particles.

Drdlik et al. [86] used electrophoretic deposition to prepare HAp/ $\mathrm{ZrO}_{2}$ microfiber with controlled fracture and microporosity properties. Vickers hardness and elastic modulus of composites enhanced with dispersions milling time prior to electrophoretic deposition and were reduced with the $\mathrm{ZrO}_{2}$ microfibers amount in the coatings, which is related to the density of composites. As a result of tougher $\beta$-TCP phase, finer microstructure, and the existence of orientated microfibers of zirconia, fracture toughness of the composites increased significantly compared to pure HAp.

Farnoush et al. [87] prepared HA/YSZ nanocomposite coatings on
Ti-6Al-4 V substrate using electrophoretic deposition and studied the stability of suspension and its effect on bonding electrochemical behavior and bonding strength. According to the obtained results, incorporation of $20 \mathrm{wt}$ \% YSZ resulted in the reduction of corrosion rate of coated specimens, whereas linear polarization resistance and corrosion potential increased.

\subsection{Sputter coating method}

Sputter coating technique is a kind of vapor deposition technique, in which high energy particles are ejected from a target and bombard a substance and is appropriate for thin coatings. For elimination of the substance from the target with negative charge, a gas plasma including xenon, krypton, neon and, argon is used and then the particles are deposited on the substrate (Fig. 6) [30].

Kong et al. [88] used magnetron sputtering for the preparation of HAp-zirconia coatings on Ti6Al4V. They proposed that the porous surface of the deposited coating is suitable for conduction of bone tissue growth. The bonding strength decreased by increasing HAp content and the residual stress reduced by appropriate increasing of HAp contents.

Ozeki et al. [89] fabricated thin films of HAp on zirconia using a sputtering technique. During hydrothermal treatment, the recrystallization of coated films occurred to decrease dissolution. After the films recrystallized under the hydrothermal treatment, bone formation area on the coating for both the $\mathrm{Ti}$ and $\mathrm{ZrO}_{2}$ substrates increased. This value was reported to be higher for the $\mathrm{ZrO}_{2}$ substrate. Table 1 summarizes the applied methods to prepare $\mathrm{HAp}$-coated $\mathrm{ZrO}_{2}$ for potential dental implant.

\section{Conclusions and future insights}

Although hydroxyapatite (HAp) is highly biocompatible, it has low mechanical properties. Instead, zirconia exhibits bioactivity, biocompatibility, and good mechanical and aesthetic properties enhancing the quality of the dental implants. Thus, HAp incorporated in zirconia provide high stability and protection in long time promoting integration of the dental implants. These composites are promising novel bone restorative materials having properties similar to human bone. Furthermore, the surface modification of zirconia composites can be obtained by different types of HAp coatings. Therefore, these materials can be considered as 
alternatives to conventional counterparts in dentistry such as titanium and its alloys due to their advantages in dental implant applications.

\section{Acknowledgments}

The authors received no financial support for the research, authorship and/or publication of this article.

\section{Conflict of Interest}

All authors declare no conflicts of interest in this paper.

\section{REFERENCES}

[1] G. Rajan, R. Raju, S. Jinachandran, P. Farrar, J. Xi, B.G. Prusty, Polymerisation Shrinkage Profiling of Dental Composites using Optical Fibre Sensing and their Correlation with Degree of Conversion and Curing Rate, Scientific Reports 9(1) (2019) 3162.

[2] K. Cho, G. Wang, Raju, J. Fang, G. Rajan, M.H. Stenzel, P. Farrar, B.G. Prusty, Selective Atomic-Level Etching on Short S-Glass Fibres to Control Interfacial Properties for Restorative Dental Composites, Scientific Reports 9(1) (2019) 3851. [3] A.A. Pérez-Mondragón, C.E. Cuevas-Suárez, J.A. González-López, N. Trejo-Carbajal, M. Meléndez-Rodríguez, A.M. Herrera-González, Preparation and evaluation of a BisGMA-free dental composite resin based on a novel trimethacrylate monomer, Dental Materials 36(4) (2020) 542-550.

[4] Y. Boussès, N. Brulat-Bouchard, P.-O. Bouchard, H. Abouelleil, Y. Tillier, The-oretical prediction of dental composites yield stress and flexural modulus based on filler volume ratio, Dental Materials 36(1) (2020) 97-107.

[5] S.V. Palagummi, T. Hong, Z. Wang, C.K. Moon, M.Y.M. Chiang, Resin viscos-ity determines the condition for a valid exposure reciprocity law in dental compos-ites, Dental Materials 36(2) (2020) 310-319.

[6] A.P. Fugolin, D. Sundfeld, J.L. Ferracane, C.S. Pfeifer, Toughening of Dental Composites with Thiourethane-Modified Filler Interfaces, Scientific Reports 9(1) (2019) 2286 .

[7] E. Habib, R. Wang, J. Zhu, Dental Nanocomposites, 1st edition, Advances in Nanostruc-tured Composites: Volume 1: Carbon Nanotube and Graphene Composites,USA, 2019.

[8] S.-N. Zhao, D.-L. Yang, D. Wang, Y. Pu, Y. Le, J.-X. Wang, J.-F. Chen, Design and efficient fabrication of micro-sized clusters of hydroxyapatite nanorods for dental resin composites, Journal of Materials Science 54(5) (2019) 3878-3892.

[9] L. Bohner, M. Hanisch, J. Kleinheinz, S. Jung, Dental implants in growing patients: a systematic review, British Journal of Oral and Maxillofacial Surgery 57(5) (2019) 397-406.

[10] A.-D. Draghici, C. Busuioc, A. Mocanu, A.-I. Nicoara, F. Iordache, S.-I. Jinga, Composite scaffolds based on calcium phosphates and barium titanate obtained through bacterial cellulose templated synthesis, Materials Science and Engineer-ing: C 110 (2020) 110704.

[11] P. Kumar, M. Saini, B.S. Dehiya, A. Umar, A. Sindhu, H. Mohammed, Y. Al-Hadeethi, Z. Guo, Fabrication and in-vitro biocompatibility of freeze-dried CTS-nHA and CTS-nBG scaffolds for bone regeneration applications, Internation-al Journal of Biological Macromolecules 149 (2020) 1-10.

[12] Y. Chen, P. Han, A. Dehghan-Manshadi, D. Kent, S. Ehtemam-Haghighi, C. Jowers, M. Bermingham, T. Li, J. Cooper-White, M.S. Dargusch, Sintering and biocompatibility of blended elemental Ti-xNb alloys, Journal of the Mechanical Behavior of Biomedical Materials 104 (2020) 103691

[13] A.H. Shahbaz, M. Esmaeilian, R. NasrAzadani, K. Gavanji, The effect of MgF2 addition on the mechanical properties of hydroxyapatite synthesized via powder metallurgy, Journal of Composites and Compounds 1(1) (2019) 16-21.

[14] E. Asadi, A. Fassadi Chimeh, S. Hosseini, S. Rahimi, B. Sarkhosh, L. Bazli, R. Bashiri, A.H. Vakili Tahmorsati, A review of clinical applications of graphene quantum dot-based composites, Journal of Composites and Compounds 1(1) (2019) 31-40

[15] Z.-K. Cui, S. Kim, J.J. Baljon, B.M. Wu, T. Aghaloo, M. Lee, Microporous methacrylated glycol chitosan-montmorillonite nanocomposite hydrogel for bone tissue engineering, Nature Communications 10(1) (2019) 3523.

[16] Y. Wang, N. Sun, Y. Zhang, B. Zhao, Z. Zhang, X. Zhou, Y. Zhou, H. Liu, Y. Zhang, J. Liu, Enhanced osteogenic proliferation and differentiation of human ad-ipose-derived stem cells on a porous n-HA/PGS-M composite scaffold, Scientific Reports 9(1) (2019) 7960.

[17] A. Esmaeilkhanian, F. Sharifianjazi, A. Abouchenari, A. Rouhani, N. Parvin, M. Irani, Synthesis and characterization of natural nano-hydroxyapatite derived from turkey femur-bone waste, Applied biochemistry and biotechnology 189(3)
(2019) 919-932.

[18] J. Soares da Silva, T.R. Machado, T.A. Martins, M. Assis, C.C. Foggi, N.G. Macedo, H. Beltrán-Mir, E. Cordoncillo, J. Andrés, E. Longo, $\alpha$-AgVO3 Decorated by Hydroxyapatite $\left(\mathrm{Ca} 10\left(\mathrm{PO}_{4}\right) 6(\mathrm{OH}) 2\right)$ : Tuning Its Photoluminescence Emissions and Bactericidal Activity, Inorganic Chemistry 58(9) (2019) 5900-5913.

[19] X. Guo, D. Li, Synthesis of Hydroxyapatite Containing some Trace Amounts Elements in Simulated Body Fluids, Iranian Journal of Chemistry and Chemical Engineering (IJCCE) 38(1) (2019) 83-91.

[20] M. Mansoorianfar, M. Mansourianfar, M. Fathi, S. Bonakdar, M. Ebrahimi, E.M. Zahrani, A. Hojjati-Najafabadi, D. Li, Surface modification of orthopedic implants by optimized fluorine-substituted hydroxyapatite coating: Enhancing cor-rosion behavior and cell function, Ceramics International 46(2) (2020) 21392146.

[21] A. Veiga, F. Castro, C.C. Reis, A. Sousa, A.L. Oliveira, F. Rocha, Hydroxy-apatite/sericin composites: A simple synthesis route under near-physiological con-ditions of temperature and $\mathrm{pH}$ and preliminary study of the effect of sericin on the biomineralization process, Materials Science and Engineering: C 108 (2020) 110400.

[22] K. Wongsawichai, A. Kingkaew, A. Pariyaisut, S. Khondee, Porous Hydroxy-apatite/Chitosan/Carboxymethyl Cellulose Scaffolds with Tunable Microstruc-tures for Bone Tissue Engineering, Key Engineering Materials 819 (2019) 9-14.

[23] C.Y. Goh, S.S. Lim, K.Y. Tshai, A.W.Z.Z. El Azab, H.-S. Loh, Fabrication and in vitro biocompatibility of sodium tripolyphosphate-crosslinked chitosanhy-droxyapatite scaffolds for bone regeneration, Journal of Materials Science 54(4) (2019) 3403-3420.

[24] Gunawarman, J. Affi, Y. Yetri, Ilhamdi, D. Juliadmi, N.F. Nuswantoro, H. Fajri, A. Ahli, R. Gundini, H. Nur, Synthesis and characterization of calcium pre-cursor for hydroxyapatite synthesis from blood clam shell (Anadara antiquata) using planetary ball mill process, IOP Conference Series: Materials Science and Engineering 602 (2019) 012072.

[25] P. Galindo-Moreno, M. Padial-Molina, L. Lopez-Chaichio, L. Gutiérrez-Garrido, N. Martín-Morales, F. O'Valle, Algae-derived hydroxyapatite behavior as bone biomaterial in comparison with anorganic bovine bone: A split-mouth clinical, radiological, and histologic randomized study in humans, Clinical Oral Implants Research 31(6) (2020) 536-548.

[26] H.L. Jaber, A.S. Hammood, N. Parvin, Synthesis and characterization of hy-droxyapatite powder from natural Camelus bone, Journal of the Australian Ceram-ic Society 54(1) (2018) 1-10.

[27] S.M.B. Nabavi, M.R. Shushizadeh, A. Behfar, M.G. Ashrafi, Persian Gulf Corals: A New Hydroxyapatite Bioceramics in Medicine, International Journal of Pharmaceutical and Phytopharmacological Research (eIJPPR) 7(5) (2017) 59-64. [28] N. Lagopati, S. Agathopoulos, Hydroxyapatite Scaffolds Produced from Cut-tlefish Bone via Hydrothermal Transformation for Application in Tissue Engineer-ing and Drug Delivery Systems, in: A.H. Choi, B. Ben-Nissan (Eds.), MarineDe-rived Biomaterials for Tissue Engineering Applications, Springer Singapore, Singapore, 2019, pp. 179-205.

[29] A. Pal, S. Paul, A.R. Choudhury, V.K. Balla, M. Das, A. Sinha, Synthesis of hydroxyapatite from Lates calcarifer fish bone for biomedical applications, Mate-rials Letters 203 (2017) 89-92.

[30] A. Nasar, 8 - Hydroxyapatite and its coatings in dental implants, in: A.M. Asiri, Inamuddin, A. Mohammad (Eds.), Applications of Nanocomposite Materials in Dentistry, Woodhead Publishing,London, 2019, pp. 145-160.

[31] J. Yazdani, E. Ahmadian, S. Sharifi, S. Shahi, S.M. Dizaj, A short view on nanohydroxyapatite as coating of dental implants, Biomedicine \& Pharmacother-apy 105 (2018) 553-557.

[32] A. Klinge, D. Khalil, B. Klinge, B. Lund, A. Naimi-Akbar, S. Tranaeus, M. Hultin, Prophylactic antibiotics for staged bone augmentation in implant dentistry, Acta Odontologica Scandinavica 78(1) (2020) 64-73.

[33] R. Lieber, N. Pandis, C.M. Faggion Jr, Reporting and handling of incomplete outcome data in implant dentistry: A survey of randomized clinical trials, Journal of Clinical Periodontology 47(2) (2020) 257-266.

[34] J. Carpentieri, G. Greenstein, J. Cavallaro, Hierarchy of restorative space required for different types of dental implant prostheses, The Journal of the American Dental Association 150(8) (2019) 695-706.

[35] M. Buciumeanu, D. Faria, J. Mesquita-Guimarães, F. Silva, Tribological char-acterization of bioactive zirconia composite layers on zirconia structures, Ceram-ics International 44(15) (2018) 18663-18671.

[36] A. Pakseresht, H.A. Baghbaderani, R. Yazdani-Rad, Role of different fractions of nano-size $\mathrm{SiC}$ and milling time on the microstructure and mechanical properties of Al-SiC nanocomposites, Transactions of the Indian Institute of Metals 69(5) (2016) 1007-1014. 
[37] M.D. Chermahini, M. Rahimipour, A. Pakseresht, Microstructure and mag-netic properties of nanostructured $\mathrm{Fe}-\mathrm{Co}$ powders prepared by series of milling and annealing treatments, Advanced Powder Technology 25(1) (2014) 462466.

[38] K. Shirvanimoghaddam, E. Ghasali, A. Pakseresht, S. Derakhshandeh, M. Alizadeh, T. Ebadzadeh, M. Naebe, Super hard carbon microtubes derived from natural cotton for development of high performance titanium composites, Journal of Alloys and Compounds 775 (2019) 601-616.

[39] Z. Özkurt, E. Kazazoğlu, Zirconia dental implants: a literature review, Journal of oral implantology 37(3) (2011) 367-376

[40] S. Rahimi, F. SharifianJazi, A. Esmaeilkhanian, M. Moradi, A.H. Safi Samghabadi, Effect of $\mathrm{SiO}_{2}$ content on $\mathrm{Y}-\mathrm{TZP} / \mathrm{Al}_{2} \mathrm{O}_{3}$ ceramic-nanocomposite properties as potential dental applications, Ceramics International 46(8, Part A) (2020) 10910-10916.

[41] M. Nejati, M. Rahimipour, I. Mobasherpour, A. Pakseresht, Microstructural analysis and thermal shock behavior of plasma sprayed ceria-stabilized zirconia thermal barrier coatings with micro and nano $\mathrm{Al}_{2} \mathrm{O}_{3}$ as a third layer, Surface and Coatings Technology 282 (2015) 129-138.

[42] N. Pourmohammadie Vafa, B. Nayebi, M. Shahedi Asl, M. Jaberi Zamharir, M. Ghassemi Kakroudi, Reactive hot pressing of $\mathrm{ZrB}_{2}$-based composites with changes in $\mathrm{ZrO}_{2} / \mathrm{SiC}$ ratio and sintering conditions. Part II: Mechanical behavior, Ceramics International 42(2, Part A) (2016) 2724-2733.

[43] A. Apratim, P. Eachempati, K.K.K. Salian, V. Singh, S. Chhabra, S. Shah, Zirconia in dental implantology: A review, Journal of International Society of Pre-ventive \& Community Dentistry 5(3) (2015) 147.

[44] A. Hafezeqoran, R. Koodaryan, Effect of Zirconia Dental Implant Surfaces on Bone Integration: A Systematic Review and Meta-Analysis, BioMed Research International 2017 (2017) 9246721.

[45] S.P. Victor, C.K.S. Pillai, C.P. Sharma, 1 - Biointegration: an introduction, in: C.P. Sharma (Ed.), Biointegration of Medical Implant Materials (Second Edition), Woodhead Publishing, London, 2020, pp. 1-16.

[46] T.J. Matsumoto, S.-H. An, T. Ishimoto, T. Nakano, T. Matsumoto, S. Imazato, Zirconia-hydroxyapatite composite material with micro porous structure, Dental materials 27(11) (2011) e205-e212.

[47] J. Izquierdo, G. Bolat, N. Cimpoesu, L.C. Trinca, D. Mareci, R.M. Souto, Electrochemical characterization of pulsed layer deposited hydroxyapatite-zirco-nia layers on Ti-21Nb-15Ta-6Zr alloy for biomedical application, Applied Surface Science 385 (2016) 368-378

[48] B. Bulut, Z. Erkmen, E. Kayali, Biocompatibility of Hydroxyapatite-Alumina and Hydroxyapatite-Zirconia Composite including Commercial Inert Glass (CIG) as a Ternary Component, J. Ceram. Sci. Tech 7(03) (2016) 263-276.

[49] C.H. Leong, A. Muchtar, C.Y. Tan, M. Razali, N.F. Amat, Sintering of Hydroxyapatite/Yttria Stabilized Zirconia Nanocomposites under Nitrogen Gas for Dental Materials, Advances in Materials Science and Engineering 2014 (2014) 367267.

[50] O. Carvalho, F. Sousa, S. Madeira, F. Silva, G. Miranda, HAp-functionalized zirconia surfaces via hybrid laser process for dental applications, Optics \& Laser Technology 106 (2018) 157-167.

[51] G. Gergely, F.C. Sahin, G. Göller, O. Yücel, C. Balázsi, Microstructural and mechanical investigation of hydroxyapatite-zirconia nanocomposites prepared by spark plasma sintering, Journal of the European Ceramic Society 33(12) (2013) 2313-2319.

[52] V.T. Targhi, H. Omidvar, S.M.M. Hadavi, F. Sharifianjazi, Microstructure and hot corrosion behavior of hot dip siliconized coating on Ni-base superalloy IN738LC, Materials Research Express 7(5) (2020) 056527.

[53] M. Barekat, R.S. Razavi, F. Sharifianjazi, Synthesis and the surface resistivity of carbon black pigment on black silicone thermal control coating, Synthesis and Reactivity in Inorganic, Metal-Organic, and Nano-Metal Chemistry 45(4) (2015) 502-506.

[54] L. Bazli, M. Siavashi, A. Shiravi, A review of carbon nanotube/TiO2 composite prepared via sol-gel method, Journal of Composites and Compounds 1(1) (2019) 1-9.

[55] A.R. Rouhani, A.H. Esmaeil-Khanian, F. Davar, S. Hasani, The effect of agarose content on the morphology, phase evolution, and magnetic properties of $\mathrm{CoFe} 2 \mathrm{O} 4$ nanoparticles prepared by sol-gel autocombustion method, International Journal of Applied Ceramic Technology 15(3) (2018) 758-765.

[56] V. Salimian Rizi, F. Sharifianjazi, H. Jafarikhorami, N. Parvin, L. Saei Fard, M. Irani, A. Esmaeilkhanian, Sol-gel derived $\mathrm{SnO}_{2} / \mathrm{Ag}_{2} \mathrm{O}$ ceramic nanocomposite for $\mathrm{H}_{2}$ gas sensing applications, Materials Research Express 6(11) (2019) 1150g2. [57] A.H. Pakseresht, Microstructural Investigation of $\mathrm{BaTiO}_{3}$ Plasma Sprayed Coating Deposited by Splash and Disk-Like Splats, Journal of Environmental Friendly Materials 2(1) (2018) 1-6.
[58] M. Heydari, M.R. Vaezi, A.A. Behnamghader, A.H. Pakseresht, M. Sarmast, Hydroxyapatite/silica Nanopowders Deposition on Ti Substrate by Plasma Spray Method, Advanced Ceramics Progress 3(4) (2017) 21-24.

[59] A. Jam, S.M.R. Derakhshandeh, H. Rajaei, A.H. Pakseresht, Evaluation of microstructure and electrochemical behavior of dual-layer NiCrAlY/mullite plasma sprayed coating on high silicon cast iron alloy, Ceramics International 43(16) (2017) 14146-14155

[60] H. Salimkhani, P. Palmeh, A.B. Khiabani, E. Hashemi, S. Matinpour, H. Salimkhani, M.S. Asl, Electrophoretic deposition of spherical carbonyl iron parti-cles on carbon fibers as a microwave absorbent composite, Surfaces and Interfaces 5 (2016) 1-7.

[61] R.B. Osman, M.V. Swain, A critical review of dental implant materials with an emphasis on titanium versus zirconia, Materials 8(3) (2015) 932-958.

[62] C. Leong, K. Lim, A. Muchtar, N. Yahaya, Decomposition of hydroxyapatite in hydroxyapatite/zirconia composites for dental applications, Advanced Materials Research, Trans Tech Publ, Switzerland, 2013, pp. 1664-1668.

[63] C. Ergun, Enhanced phase stability in hydroxylapatite/zirconia composites with hot isostatic pressing, Ceramics International 37(3) (2011) 935-942.

[64] K.F. Lim, M. Andanastuti, R. Mustaffa, C.Y. Tan, Sintering of HA/Zirconia composite for biomedical and dental applications: A Review, Advanced Materials Research, Trans Tech Publ, Switzerland, 2013, pp. 290-295.

[65] J. Mesquita-Guimarães, R. Detsch, A.C. Souza, B. Henriques, F.S. Silva, A.R. Boccaccini, O. Carvalho, Cell adhesion evaluation of laser-sintered HAp and 45S5 bioactive glass coatings on micro-textured zirconia surfaces using MC3T3-E1 osteoblast-like cells, Materials Science and Engineering: C 109 (2020) 110492

[66] N. Cimpoeşu, L.C. Trincă, G. Dascălu, S. Stanciu, S.O. Gurlui, D. Mareci, Electrochemical Characterization of a New Biodegradable FeMnSi Alloy Coated with Hydroxyapatite-Zirconia by PLD Technique, Journal of Chemistry 2016 (2016) 9520972.

[67] F. Sharifianjazi, N. Parvin, M. Tahriri, Synthesis and characteristics of solgel bioactive $\mathrm{SiO}_{2}-\mathrm{P}_{2} \mathrm{O}_{5}-\mathrm{CaO}-\mathrm{Ag}_{2} \mathrm{O}$ glasses, Journal of Non-Crystalline Solids 476 (2017) 108-113.

[68] F. Sharifianjazi, N. Parvin, M. Tahriri, Formation of apatite nano-needles on novel gel derived $\mathrm{SiO}_{2}-\mathrm{P}_{2} \mathrm{O}_{5}-\mathrm{CaO}-\mathrm{SrO}-\mathrm{Ag}_{2} \mathrm{O}$ bioactive glasses, Ceramics Interna-tional 43(17) (2017) 15214-15220.

[69] Z. Goudarzi, N. Parvin, F. Sharifianjazi, Formation of hydroxyapatite on surface of $\mathrm{SiO}_{2}-\mathrm{P}_{2} \mathrm{O}_{5}-\mathrm{CaO}-\mathrm{SrO}-\mathrm{ZnO}$ bioactive glass synthesized through sol-gel route, Ceramics International 45(15) (2019) 19323-19330.

[70] M.S.N. Shahrbabak, F. Sharifianjazi, D. Rahban, A. Salimi, A Comparative Investigation on Bioactivity and Antibacterial Properties of Sol-Gel Derived 58S Bioactive Glass Substituted by Ag and Zn, Silicon 11(6) (2019) 2741-2751.

[71] F.S. Jazi, N. Parvin, M. Tahriri, M. Alizadeh, S. Abedini, M. Alizadeh, The relationship between the synthesis and morphology of $\mathrm{SnO}_{2}-\mathrm{Ag}_{2} \mathrm{O}$ nanocomposite, Synthesis and Reactivity in Inorganic, Metal-Organic, and Nano-Metal Chemistry 44(5) (2014) 759-764.

[72] S. Abedini, N. Parvin, P. Ashtari, F. Jazi, Microstructure, strength and $\mathrm{CO}_{2}$ separation characteristics of $\alpha$-alumina supported $\gamma$-alumina thin film membrane, Advances in Applied Ceramics 112(1) (2013) 17-22.

[73] H. Vasconcelos, M. Barreto, Tailoring the microstructure of sol-gel derived hydroxyapatite/zirconia nanocrystalline composites, Nanoscale Res Lett 6(1) (2011) $1-5$.

[74] S. Salehi, M. Fathi, Fabrication and characterization of sol-gel derived hy-droxyapatite/zirconia composite nanopowders with various yttria contents, Ceram-ics International 36(5) (2010) 1659-1667.

[75] F. Bollino, E. Armenia, E. Tranquillo, Zirconia/hydroxyapatite composites synthesized via Sol-Gel: Influence of hydroxyapatite content and heating on their biological properties, Materials 10(7) (2017) 757.

[76] M. Catauro, F. Bollino, E. Tranquillo, R. Tuffi, A. Dell'Era, S.V. Ciprioti, Morphological and thermal characterization of zirconia/hydroxyapatite compos-ites prepared via sol-gel for biomedical applications, Ceramics International 45(2) (2019) 2835-2845.

[77] S.D. Jin, S.C. Um, J.K. Lee, Surface Modification of Zirconia Substrate by Calcium Phosphate Particles Using Sol-Gel Method, Journal of nanoscience and nanotechnology 15(8) (2015) 5946-5950.

[78] R.T. Candidato Jr, P. Sokołowski, L. Pawłowski, G. Lecomte-Nana, C. Con-stantinescu, A. Denoirjean, Development of hydroxyapatite coatings by solution precursor plasma spray process and their microstructural characterization, Surface and Coatings Technology 318 (2017) 39-49.

[79] A. Pakseresht, M. Rahimipour, M. Vaezi, M. Salehi, Effect of plasma spray parameters on the microstructure anddielectric properties of barium titanate coating, DENT 18 (2014) 21

[80] A.H. Pakseresht, M.R. Rahimipour, M.R. Vaezi, M. Salehi, Effect of mor- 
phol-ogy and non-bounded interface on dielectric properties of plasma sprayed $\mathrm{BaTiO}_{3}$ coating, Journal of advanced materials and processing (journal of materials sci-ence) 2(4) (2014) 25-32.

[81] A. Pakseresht, M. Rahimipour, M. Vaezi, M. Salehi, Thermal plasma spheroid-ization and spray deposition of barium titanate powder and characterization of the plasma sprayable powder, Materials Chemistry and Physics 173 (2016) 395403.

[82] M.F. Hasan, J. Wang, C. Berndt, Evaluation of the mechanical properties of plasma sprayed hydroxyapatite coatings, Applied surface science 303 (2014) 155162

[83] A. Rafieerad, A. Bushroa, B. Nasiri-Tabrizi, S. Baradaran, S. Shahtalebi, S. Khanahmadi, M. Afshar-Mohajer, J. Vadivelu, F. Yusof, W. Basirun, In-vitro bioassay of electrophoretically deposited hydroxyapatite-zirconia nanocomposite coating on Ti-6Al-7Nb implant, Advances in Applied Ceramics 116(6) (2017) 293-306.

[84] M. Sandhyarani, N. Rameshbabu, K. Venkateswarlu, Fabrication, characteri-zation and in-vitro evaluation of nanostructured zirconia/hydroxyapatite compos-ite film on zirconium, Surface and Coatings Technology 238 (2014) 58-67.
[85] K. Sakthiabirami, J.W. Kim, J.H. Kang, K.J. Jang, G.J. Oh, J.G. Fisher, K.D. Yun, H.P. Lim, S.W. Park, Tailoring interfacial interaction through glass fusion in glass/zinc-hydroxyapatite composite coatings on glass-infiltrated zirconia, Ceram-ics International 44(14) (2018) 16181-16190.

[86] D. Drdlik, M. Slama, H. Hadraba, J. Cihlar, Hydroxyapatite/zirconia-micro-fibre composites with controlled microporosity and fracture properties prepared by electrophoretic deposition, Ceramics International 41(9) (2015) 11202-11212.

[87] H. Farnoush, Z. Rezaei, Effect of suspension stability on bonding strength and electrochemical behavior of electrophoretically deposited HA-YSZ nanostruc-tured composite coatings, Ceramics International 43(15) (2017) 1188511897.

[88] D.-j. Kong, D. Long, Y.-z. Wu, C.-z. Zhou, Mechanical properties of hydroxy-apatite-zirconia coatings prepared by magnetron sputtering, Transactions of Non-ferrous Metals Society of China 22(1) (2012) 104-110

[89] K. Ozeki, T. Goto, H. Aoki, T. Masuzawa, Fabrication of hydroxyapatite thin films on zirconia using a sputtering technique, Bio-medical materials and engineer-ing 24(5) (2014) 1793-1802. 